\title{
Assessment of plantar pressure and balance in patients with diabetes
}

Daniela M.C. Anjos ${ }^{1}$, Luciana P.O. Gomes ${ }^{1}$, Luciana M.M. Sampaio², João C.F. Correa², Claudia S. Oliveira ${ }^{2}$

\begin{abstract}
${ }^{1}$ Centro Universitário de Belo Horizonte, UNI-BH, Belo Horizonte, Minas Gerais, Brazil ${ }^{2}$ Rehabilitation Sciences Master's Program, Universidade Nove de Julho, UNINOVE, São Paulo, Brazil
\end{abstract}

Submitted: 27 April 2009

Accepted: 9 June 2009

Arch Med Sci 2010; 6, 1: 43-48

DOI 10.5114/aoms.2010.13506

Copyright $\odot 2010$ Termedia \& Banach

\begin{abstract}
Introduction: Patients with diabetes for more than 10 years may have an increase in peak plantar pressure, considerable postural oscillation, balance deficit, alterations in gait pattern and an increased risk of falls. The aim of the present study was to assess the correlation between plantar pressure distribution and balance in patients with diabetes using a pressure platform (Footwork).

Material and methods: The study was carried out at the Human Movement Clinic of the Centro Universitário de Belo Horizonte (Brazil). The sample was made up of 18 right-handed individuals with type 2 diabetes -14 females and 4 males with an average age of $58.72 \pm 9.54$ and an average of $18.56 \pm 6.61$ years since diagnosis.

Result: Data analysis revealed that greater peak plantar pressure on the right hindfoot led to greater radial displacement $(\mathrm{Rd})(r=0.2022)$ and greater displacement velocity $(r=0.2240)$. Greater peak plantar pressure on the left hindfoot also led to greater displacement velocity $(P)(r=0.5728)$ and radial displacement (RD) $(r=0.1972)$. A positive correlation was found between time elapsed since diagnosis and peak midfoot pressure $(r=0.3752)$ on the right and left side as well as between $\mathrm{BMI}$ and plantar pressure on all regions of the foot. Conclusions: The data reveal a correlation between postural oscillation and peak plantar pressure on the hindfoot.
\end{abstract}

Key words: diabetes, baropodometry, balance, stabilometry, diabetic neuropathy, plantar pressure.

\section{Introduction}

Diabetes mellitus is characterized by a relative or absolute deficiency in the hormone insulin, resulting in a rise in blood sugar levels. The term diabetes mellitus describes a metabolic disorder of multiple aetiology characterized by chronic hyperglycaemia, as established by the American Diabetes Association (ADA). Peripheral diabetic neuropathy is a frequent complication in patients with diabetes and affects their quality of life [1-3]. The classification of diabetes mellitus includes a stage of normoglycaemia, classifying individuals who have evidence of pathological processes that may lead to diabetes mellitus or in whom a reversal of the hyperglycaemia has occurred [3].

A large number of factors have been identified as possibly responsible for the increase in plantar pressure in the feet of diabetics. Such factors include an increase in body weight, limitation in joint mobility, thickness of the plantar tissue, change in tissue mobility, change in muscle strength,
Corresponding author:

Prof. Claudia Santos Oliveira Rua Itapicuru 380 apto 111, Perdizes

São Paulo, SP, Brazil

CEP 05006-000

Phone: 551138681681

Fax: 551138681681

E-mail: csantos@uninove.br 
motor/sensory neuropathy, and change in structure/deformity of the feet. It is well documented that plantar pressure in diabetics is greater than in non-diabetics [4-7].

Foot exams are performed in a standing position using electronic podometry, which is an objective, quantitative method for measuring and comparing pressure at different points of the plantar region in a static position. This exam allows the quantification of pressure in the forefoot, midfoot and hindfoot [8-10].

Frequent change in tactile sensitivity of the feet in peripheral neuropathy is associated with a risk of falls in 3 to $6 \%$ of cases. Individuals with diabetic neuropathy have a higher rate of falls, greater deviations in posture when standing and greater area of oscillation in comparison to individuals without this condition [11, 12]. Stabilometry measures and records the continuous oscillation of the human body through displacement speed and radial displacement [13]. It is likely that there is a relationship between mean peak plantar pressure in the different regions of the feet, displacement speed and radial displacement, as there is an increase in plantar pressure and greater oscillation in diabetic individuals with increase in time since diagnosis. The understanding of this process will certainly improve assessment procedures and physiotherapy treatment as well as provide an early approach to the prevention of falls and the much-dreaded diabetic ulcers.

The aim of the study was to determine the correlation between changes in plantar pressure and balance in diabetic patients based on podometric and stabilometric parameters.

\section{Material and methods}

A non-controlled, descriptive, prospective, crosssectional study was carried out at the Human Movement Clinic of the Centro Universitário de Belo Horizonte on the Estoril campus in the city of Belo Horizonte, Minas Gerais, Brazil. The sample was made up of 18 individuals (14 females and 4 males) with a confirmed diagnosis of type 2 diabetes and a mean age of $58.72 \pm 9.54$ years.

For the selection of the sample, the following factors were considered as inclusion criteria: clinical classification of type 2 diabetes; either gender; and capability to remain in an orthostatic position without assistance or the use of auxiliary devices. Individuals with total blindness, those diagnosed with diabetic retinopathy, those with any vision impairment that could not be corrected with lenses; and those exhibiting symptoms compatible with vestibular problems at the time of the exam, such as vertigo, dizziness or ringing in the ears, were excluded from the study. All participants signed the terms of informed consent approved by the UNIVAP Ethics Committee.
The study was carried out in two distinct phases. In the first phase, the subjects were submitted to an initial evaluation, which consisted of gathering information on personal data, patient history, type of diabetes, duration of the disease, family history, co-morbidities, visual or vestibular impairment, laboratory exams, medications in use, weight, height, shoe size and dominant side. In the second phase, the subjects were submitted to a simultaneous evaluation of plantar distribution through the podometric exam and an evaluation of balance through the stabilometric exam on a pressure plate. The equipment used was a pressure plate from the Footwork Analysis System, with 2704 sensors measuring $7.62 \times 7.62 \mathrm{~mm}$, which allows stabilometric analysis of the pressure load and contact time of the foot with the ground in either a static or dynamic erect position. The same pressure plate allows a podometric evaluation, measuring and comparing pressure in different points of the plantar region in an orthostatic position. This equipment contains a 16-bit A/D converter and sampling frequency of $250 \mathrm{~Hz}$.

The participants were instructed to remain in an orthostatic position with an unrestricted base that brought comfort, with no movements of the upper limbs and maintaining the eyes on a target attached to the wall at a distance of $1 \mathrm{~m}$ from the platform at eye level. The participants performed the test barefoot, with eyes open, and those with visual impairment used corrective lenses during the test. Each data collection time was $30 \mathrm{~s}$.

The data were analyzed using Bartlett's method in order to determine whether the standard deviations were similar. When positive, one-way analysis of variance (ANOVA) and the Tukey-Kramer test were used for multiple comparisons for parametric data. When negative, the data were considered non-parametric and the Kruskal-Wallis ANOVA and Dunn's test were used for multiple comparisons. The level of significance was set at $5 \%$. These tests were administered for comparisons between peak pressure (forefoot, midfoot and hindfoot) in the podometric analysis and displacement speed (P) and radial displacement (RD) in the stabilometric analysis. Subsequently, the calculation of Pearson's correlation coefficient $(r)$ was performed between variables in order to determine possible relationships between time since diagnosis and body mass index (BMI) with peak pressure values (forefoot, midfoot and hindfoot) in the podometric analysis and $P$ and $R D$ in the stabilometric analysis as well as between the podometric and stabilometric variables. Comparative analyses were performed using the Newinstat 2.0 program. The graphs and coefficients were generated using the Microcal Origin 6.0 program. 


\section{Results}

Table I displays the characteristics of the population studied. Two participants were classified as within the normal weight range; 8 were classified as overweight; 7 were classified as grade 1 obese; and 1 was classified as grade 2 obese. Time since the diagnosis of diabetes ranged from 8 to 28 years and was divided into 3 groups: $\mathrm{Gl}$ ( $\leq 10$ years), Gll (> 10 and $\leq 20$ years) and GIII (> 20 years). The most frequent co-morbidities in the sample were visual impairment (33\%), dyslipidaemia (44\%), arterial hypertension (89\%) and obesity (89\%). A positive correlation was found between BMI and time since diagnosis as well as between BMI and glycaemia factors (Figure 1).

The results of plantar distribution reveal that the right foot exhibited greater peak pressure in the forefoot region when compared to the midfoot and hindfoot, but the difference was only significant in relation to the midfoot ( $p=0.00005)$. The difference between the midfoot and hindfoot was also significant $(p=0.0053)$ (Figure 2). There were

Table I. Characteristics of the sample

\begin{tabular}{|c|c|c|c|c|c|c|c|c|}
\hline $\mathrm{DM} 2$ & $\begin{array}{l}\text { Time since } \\
\text { diagnosis }\end{array}$ & Age & $\begin{array}{c}\text { Weight } \\
{[\mathrm{kg}]}\end{array}$ & $\begin{array}{l}\text { Height } \\
{[\mathrm{cm}]}\end{array}$ & $\begin{array}{l}\text { Abdominal } \\
\text { circumference }\end{array}$ & $\begin{array}{c}\text { BMI } \\
{\left[\mathrm{kg} / \mathrm{m}^{2}\right]}\end{array}$ & Obesity & $\begin{array}{c}\text { Glycaemia } \\
\text { [mg/dl] }\end{array}$ \\
\hline 1 & 2 & 54.00 & 93.00 & 178.00 & 103 & 29.35 & overweight & 64 \\
\hline 2 & 1 & 62.00 & 62.50 & 177.00 & 82 & 19.95 & normal & 106 \\
\hline 3 & 3 & 68.00 & 73.00 & 153.00 & 96 & 31.19 & obese 1 & 259 \\
\hline 4 & 3 & 53.00 & 86.00 & 158.00 & 109 & 34.45 & obese 1 & 444 \\
\hline 5 & 1 & 66.00 & 67.80 & 148.00 & 103 & 30.95 & obese 1 & 123 \\
\hline 6 & 2 & 47.00 & 69.00 & 154.00 & 97 & 29.09 & overweight & 155 \\
\hline 7 & 3 & 58.00 & 54.00 & 146.00 & 95 & 25.33 & overweight & 171 \\
\hline 8 & 1 & 54.00 & 67.00 & 148.00 & 99 & 30.59 & obese 1 & 297 \\
\hline 9 & 2 & 47.00 & 79.00 & 164.00 & 105 & 29.37 & overweight & 319 \\
\hline 10 & 3 & 54.00 & 71.50 & 149.00 & 104 & 32.20 & obese 1 & 354 \\
\hline 11 & 3 & 80.00 & 64.30 & 149.00 & 104 & 28.90 & overweight & 287 \\
\hline 12 & 2 & 57.00 & 90.00 & 157.00 & & 36.51 & obese 2 & 218 \\
\hline 13 & 3 & 76.00 & 66.70 & 161.00 & 51 & 25.60 & overweight & 201 \\
\hline 14 & 2 & 57.00 & 78.50 & 150.00 & 90 & 34.88 & obese 1 & 243 \\
\hline 15 & 2 & 65.00 & 63.40 & 151.00 & 84 & 27.81 & overweight & 216 \\
\hline 16 & 3 & 47.00 & 67.50 & 152.00 & 91 & 29.22 & overweight & 197 \\
\hline 17 & 1 & 50.00 & 73.90 & 154.00 & 107 & 31.16 & obese 1 & 86 \\
\hline 18 & 2 & 62.00 & 68.00 & 165.00 & 94 & 24.97 & overweight & 98 \\
\hline Mean & & 58.72 & 71.95 & 156.33 & 94.941 & 29.53 & & 213.22 \\
\hline $\begin{array}{l}\text { Standard } \\
\text { deviation }\end{array}$ & & 9.54 & 10.06 & 9.45 & 13.73 & 3.96 & & 101.99 \\
\hline
\end{tabular}
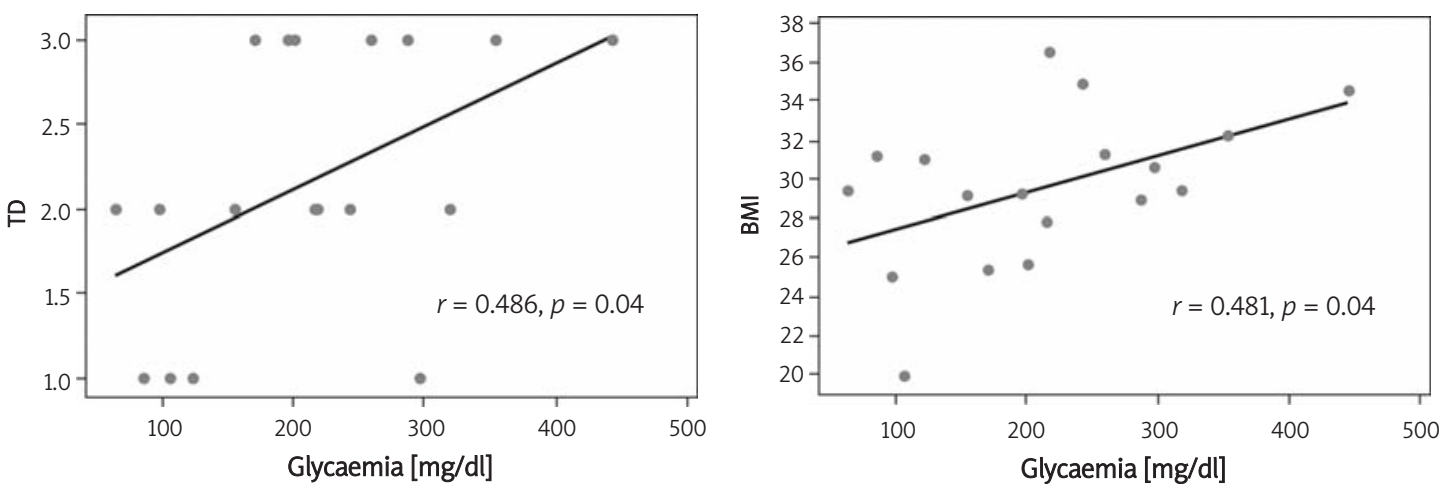

Figure 1. Correlation between BMI and time since diagnosis and between BMI and glycaemia values 


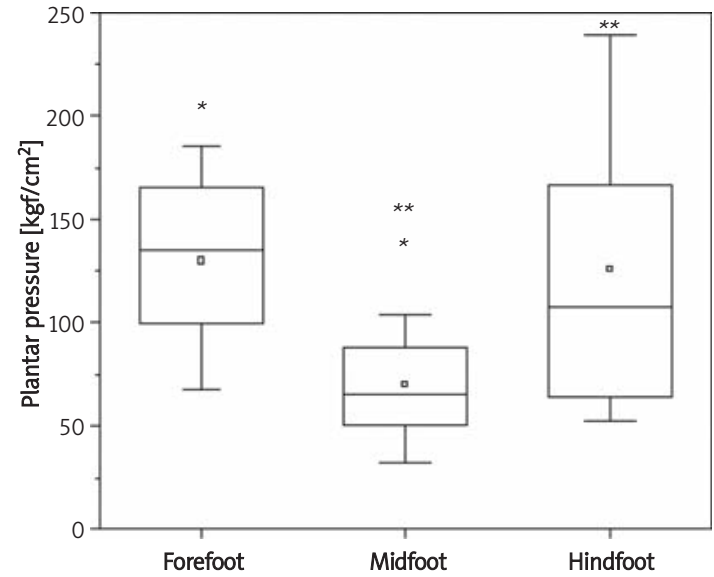

Figure 2. Mean peak plantar pressure values in the right foot $\left({ }^{*},{ }^{* *} p<0.05\right)$

significant differences in mean peak plantar pressure values between the three regions in the left foot; it was highest in the forefoot, followed in decreasing order by the hindfoot and midfoot (Figure 3). Comparing the right and left feet, there were no significant differences in plantar pressure in the forefoot or midfoot.

The results of the postural oscillation in the anterior-posterior and medial-lateral directions of the barycentre of the body and the right and left feet were analyzed to obtain the $P$ and RD. Displacement speed values were greater in the barycentre of the body, followed in decreasing order by the barycentre of the left foot and that of the right foot. The difference between barycentres of the right and left feet was statistically significant $(p=0.0026)$ (Figure 4). Regarding RD values, there was a non-significant difference between the barycentres of the right and left feet $(p>0.05)$. There was a statistically significant difference in the barycentre of the body regarding dislocation speed (Figure 3) when compared to that of the right foot

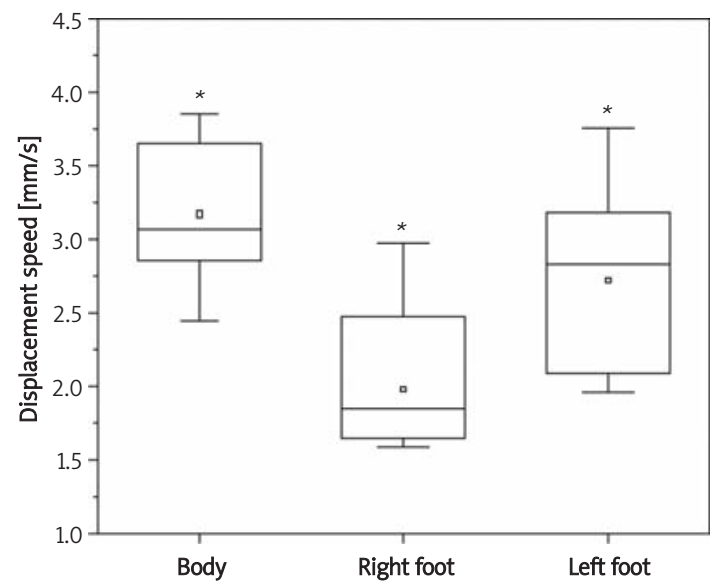

Figure 4. Mean displacement speed values in barycentre of the body as well as right and left feet $\left({ }^{*} p<0.05\right)$

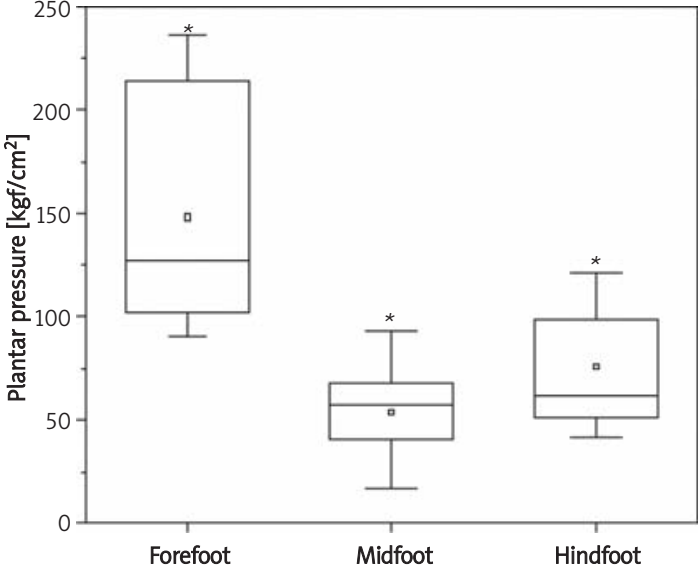

Figure 3. Mean peak plantar pressure values in the left foot $\left({ }^{*} p<0.05\right)$

( $p=0.000001)$ and left foot $(p=0.0302)$, but not with regard to radial displacement $(p>0.05)$.

A positive correlation was found between the right midfoot and time since diagnosis as well as between the left midfoot and time since diagnosis. The present study demonstrated that a greater time since diagnosis denotes greater mean peak plantar pressure in the midfoot of the right and left feet. A weak correlation was found between mean peak plantar pressure values of the right forefoot $(r=0.13752, p>0.05)$, left midfoot $(r=1538$, $p>0.05)$, left hindfoot $(r=0.1633, p>0.05)$ and BMI. There was a positive correlation between podometric parameters and BMI. Higher BMI values denoted greater mean peak plantar pressure values in the regions of the feet. A longer time since diagnosis also denoted greater displacement velocity (P) (Figure 5), thereby demonstrating a positive correlation between these variables. Greater peak plantar pressure in the right hindfoot $(r=0.2022, p>0.05)$ and left hindfoot $(r=0.5728$, $p>0.05)$ was positively correlated with radial displacement. Displacement velocity was also positively correlated with peak plantar pressure in the right hindfoot $(r=0.2240, p>0.05)$ and left hindfoot $(r=0.1972, p>0.05)$.

\section{Discussion}

A large number of studies have confirmed high plantar pressure as the main causal factor for plantar ulcers in diabetic patients [2, 14-16]. Some studies have assessed plantar pressure in diabetic patients with and without neuropathic foot ulcers compared to a control group [17-19], but generally did not examine plantar pressure in diabetic individuals with no complications and a relatively short time since diagnosis of the disease.

Pataky et al. [19] examined the distribution of plantar pressure in patients with type 2 diabetes with no microvascular or macrovascular 
complications 6 years after the onset of the disease. The authors found an increase in plantar pressure beneath the hallux and $5^{\text {th }}$ metatarsal head, whereas plantar pressure in the heel was significantly lower than in the non-diabetic controls in both feet.

The population of the present study had higher mean peak plantar pressure values in the forefoot, followed by the hindfoot, with the difference between the two regions only significant on the non-dominant side (left foot). In an analysis of load distribution in a sample of 107 individuals in an orthostatic position, Cavanagh et al. [20] found that $60.5 \%$ of the weight was distributed in the heel, $7.8 \%$ in the midfoot, $28.1 \%$ in the forefoot and $3.6 \%$ in the toes.

Caselli et al. [21] also report a tendency toward displacement of plantar pressure. The authors found an increase in plantar pressure in both the forefoot and hindfoot in diabetic individuals with peripheral neuropathy and suggest that this reflects a lack of equilibrium in the distribution of pressure in severe neuropathy (increase in the radius of plantar pressure from the forefoot to the hindfoot). As in the present study, however, the authors did not evaluate non-diabetic controls.

A number of factors have been identified as possibly responsible for the increase in plantar pressure [22], including an increase in body weight, limitation in joint mobility [3], thickness of the plantar cushion [4], changes in tissue softness, changes in muscle strength and diabetic neuropathy [5]. Diabetic neuropathy occurs in $25 \%$ of diabetic patients with 10 years since diagnosis and $50 \%$ of those with more than 20 years since diagnosis [23]. In the present study, a longer time since the diagnosis of diabetes was associated with a greater mean peak plantar pressure in the right and left midfoot and greater $\mathrm{P}$ in postural oscillation.

Falls among elderly individuals often result from accidental slipping or tripping associated with instability while walking [24]. The population of the present study was not elderly (mean age: 58.72 years), but we found an increase in oscillation speed. With an increase in the time since diagnosis, individuals with diabetes experience changes in the somatosensorial, vestibular and visual systems.

There was a weak correlation between mean plantar pressure values of the right forefoot and BMI as well as between the left midfoot and hindfoot. There was no correlation between BMI and displacement velocity $(\mathrm{P})$ or between $\mathrm{BMI}$ and RD. Cavanagh et al. [20] found no relationship between body weight and peak pressure. Thus, one may expect to find light-weight women to have plantar pressure as high as that of heavy-weight men.

In the right hindfoot, higher mean peak plantar pressure values were correlated with greater radial displacement and displacement speed. This positive correlation reveals a relationship between plantar pressure and balance in the hindfoot on the dominant side in an orthostatic position. There was also a positive correlation between peak plantar pressure values in the left hindfoot and displacement speed. When plantar pressure is greater in the hind region, an individual has greater difficulty in maintaining his/her balance.
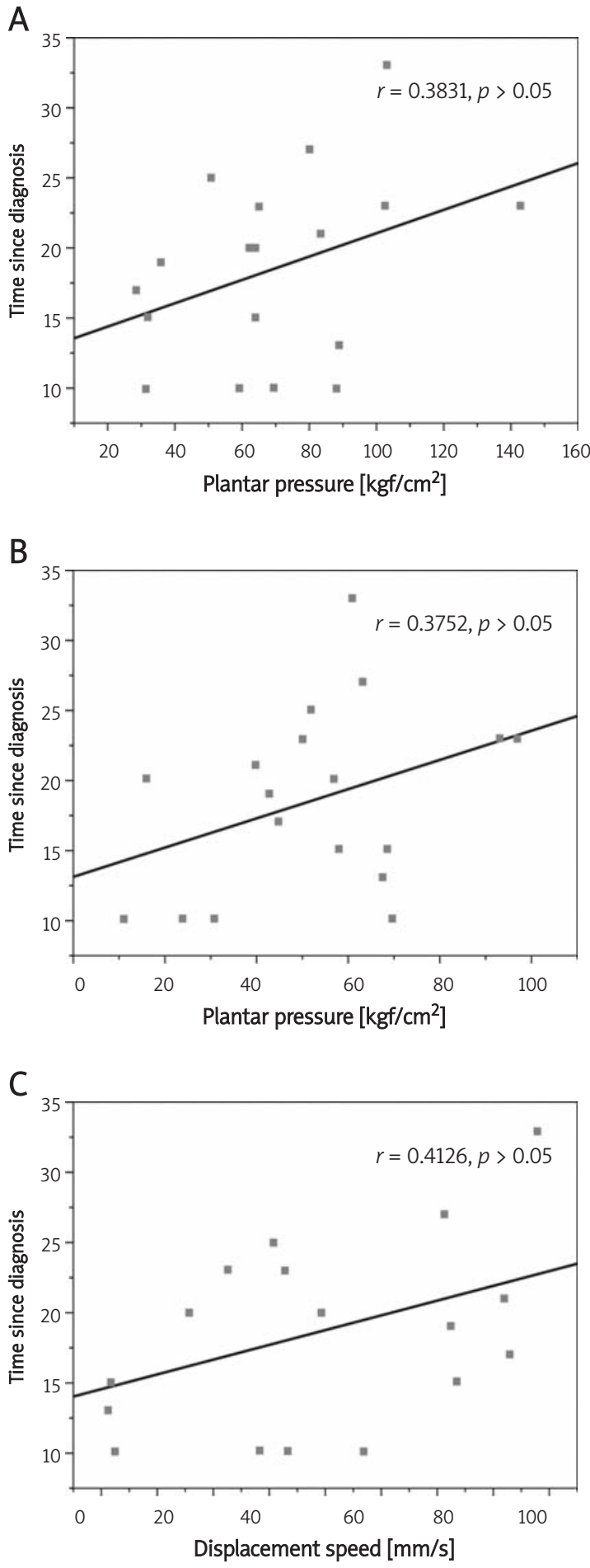

Figure 5. Correlation between mean plantar pressure and time since diagnosis 
In conclusion, the present analysis of podometric and stabilometric (displacement speed and radial displacement) parameters suggests a relationship between postural oscillation and peak plantar pressure in the hindfoot. In order to get a better understanding of this relationship, further studies should determine the relationship between these parameters in a diabetic population compared to a control group. Advances in the study of podometry and stabilometry will improve assessment procedures as well as the treatment of individuals with diabetes and can be used in the prevention of falls and diabetic ulcers.

\section{Acknowledgments}

Work carried out at the Master's Program in Rehabilitation Sciences - Universidade Nove de Julho University (UNINOVE) and the Instituto de Pesquisas e Desenvolvimento - Universidade Vale do Paraíba (UNIVAP).

\section{References}

1. Boulton AJ, Malik RA, Arezzo JC, Sosenko JM. Diabetic somatic neuropathies: a technical review. Diabetes Care 2004; 27: 1458-86.

2. Dasilva MA, Muñoz MP, González LT. Perspectiva familiar alrededor del paciente diabético. Ver Neurol, Neurocirugía y Psiquiatria 2005; 38: 63-8.

3. The Expert Committee on the Diagnosis and Classification of Diabetes Mellitus. Diabetes Care 1997; 20: 1183-97.

4. Veves A, Murray HJ, Young MJ, Boulton AJ. The risk of foot ulceration in diabetic patients with high foot pressure: a prospective study. Diabetologia 1992; 15: 660-3.

5. Fernando DJ, Masson EA, Veves A, Boulton AJ. Relationship of limited joint mobility to abnormal foot pressures and diabetic ulceration. Diabetes Care 1991; 14: 8-11.

6. Gooding GW, Stess RM, Graf PM. Sonography of the sole of the foot- evidence for loss of foot pad thickness in diabetics and it relationship to ulceration of the foot. Invest Radiol 1986; 21: 45-8.

7. Payne CB. Biomechanics of the diabetic foot- some theoretical considerations. J Am Podiatr Med Assoc 1998; 88: 285-9.

8. Sarnow MR, Veves A, Giurini JM, Rosenblum BI, Chrzan JS, Habershaw GM. In -shoe foot pressure measurements in diabetic patients with at-risk feet and in healthy subjects. Diabetes Care 1994; 17: 1002-6.

9. Veves A, Fernando DJ, Walewski P, Boulton AJ. A study of plantar pressure in a diabetic clinic population. Foot 1991; 2: 89-92.

10. Wooden MJ. Biomechanical evaluation for functional orthotics. In: Donatelli RA. The biomecnics of the foot and ankle. Philadelphia: Davis Company; 1996.

11. Chamlian TR. Medicina Física e Reabilitação: parte 1. São Paulo: EDUSP 1999; 41.

12. Libotte M. Podospie Electronique. Encyclopêdie MédicoChirurgicale: Kinésithérapie eeducation fonctionelle. Paris: Edition Scientifíques et médicales Elsevier 2001.

13. Gutierrez E, Helber M, Dealva D, Ashton-Miller J, Richardson J. Mild diabetic neuropathy affects ankle motor function. Clin Biomech (Briston, Avon) 2001; 16: 522-8.
14. Richardson JK. The clinical identification of peripheral neuropathy among older person. Arch Phys Med Rehabil 2002; 83: 1553-8.

15. Stokes IA, Faris IB, Hulton WC. The neuropathic ulcer and loads on the foot in diabetic patients. Acta Orthop Sand 1975; 46: 839-47.

16. Boulton AJ, Gries FA, Jervell JA. Guidelines for the diagnosis and outpatient management of diabetic peripheral neuropathy. Diabet Med 1998; 15: 508-14.

17. Middleton J, Sinclair P, Patton R. Accuracy of centre of pressure measurement using a piezoelectric force platform. Clin Biomech 1999; 14: 357-60.

18. Mayfield JA, Reiber GE, Sanders LF, et al. Preventive foot care in people with diabetes. Diabetes Care 1998; 21: 2161-77.

19. Lavery LA, Armstrong DG, Vela SA, et al. Pratical criteria for screening patient at high risk for diabetic foot ulceration. Arch Intern Medicine 1998; 158: 157-62.

20. D'ambrogi E, Giurato L, D'agostinho MA, et al. Contribution of plantar fascia to the increased forefoot pressure in diabetic patient. Diabetes Care 2003; 26: 1525-9.

21. Pataky Z, Assal JP, Conne P, et al. Plantar pressure distribution in type 2 diabetic patients without peripheral neuropathy and vascular disease. Diabet Med 2005; 22: 762-7.

22. Cavanagh PR, Rodgers MM, Liboshi A. Pressure distribution under symptom-free feet during barefoot standing. Foot Ankle 1987; 15: 262-7.

23. Caselli A, Pham H, Giurini JM, Armstrong DG, Veves A. The Forefoot-to-Rearfoot plantar pressure ratio is increased in severe diabetic neuropathy and can predict foot ulceration. Diabetes Care 2002; 25: 1066-71.

24. Masson EA. What causes high foot pressures in diabetes: how can they be relived? Foot 1992; 2: 212-7.

25. Pirart J. Diabetes mellitus and its degenerative complications: a prospective study of 4.400 patients observed between 1947 and 1973. Diabetes Care 1978; 1: 168-88.

26. Lord S, Clark R, Webster L. Postural stability and associated physiological factors in a population of aged persons. J Gerontol 1991; 46: 69-76. 